\title{
TCAD simulation of MIS-gated power GaN transistors
}

\author{
Erofeev Evgeny \\ Tomsk state university of control systems and \\ radioelectronics \\ Tomsk, Russia \\ erofeev@sibmail.com \\ Fedin Ivan \\ Tomsk state university of control systems and \\ radioelectronics \\ Tomsk, Russia \\ erofeev@sibmail.com
}

\author{
Kutkov Ilya \\ Research and production company Micran \\ Tomsk, Russia \\ fedina@micran.ru \\ Fedina Valeria \\ Research and production company Micran \\ Tomsk, Russia \\ fedina@micran.ru
}

\begin{abstract}
E-mode AlGaN/GaN HEMTs are generally promising candidate for switching power transistors due to their high breakdown voltage, high current density and low onresistance. The threshold voltage (Vth) of normally-off mode AIGaN/GaN HEMTs with a self-aligned p-type GaN gate can be successfully improved by inserting a $\mathrm{SiN}$ insulator between the pGaN and a Schottky gate electrode. The $V$ th can be increased from $+1.5 \mathrm{~V}$ to $+6.8 \mathrm{~V}$ by inserting of $15 \mathrm{~nm} \mathrm{SiN}$ layer. Moreover, the sub-threshold drain and on-state gate currents of p-gate GaN transistor were decreased.
\end{abstract}

Keywords-power electonics, GaN transistor, p-GaN, selfaligned, threshold voltage, Schottky, MIS-gate

\section{INTRODUCTION}

GaN based high electron mobility transistors (HEMTs) are excellent devices for application in power electronics. To realize high-efficiency and high-power inverters, low-onresistance, high drain current and high breakdown voltage devices are needed. AlGaN/GaN high electron mobility transistors are very promising for realizing such efficient electron devices [1]. High-power devices should be operated in the normally off mode to realize a fail-safe system. However, most of the AlGaN/GaN HEMTs are operated in the normally on mode. Normally off p-type gate GaN HEMTs are promising for the realization of high power and low-loss switching devices because the leakage drain current is very low at zero gate-source bias [2]. To realize fail-safe operation, the threshold voltage of normally-off mode transistors should be higher than $+2 \mathrm{~V}$ to prevent an incorrect action. Normallyoff HEMTs based on metal-insulator-semiconductor (MIS) gate structure with full recess $\mathrm{AlGaN}$ have been already reported by several groups [3]-[8]. There is low gate leakage, threshold voltage higher than one volt. But the main drawbacks of this approach are the threshold voltage instability (positive [9], or negative [10]) due to the interface/border traps in the insulator, and the time dependent dielectric breakdown of the thin insulator [11] - [14].

In this study we present TCAD simulation and experimental results of MIS-gated power GaN transistors to increase the threshold voltage and reduce gate leakage of emode power switching devices.

\section{EXPERIMENTAL}

The $\mathrm{p}-\mathrm{GaN} / \mathrm{AlGaN} / \mathrm{GaN}$ epitaxial structures produces by MOCVD on silicon substrates were used in experiments. The structures include the GaN:Fe doped buffer layer ( $2 \mathrm{um}$ ), i$\mathrm{GaN}$ channel, $\mathrm{Al}_{0.25} \mathrm{Ga}_{0.75} \mathrm{~N}$ barrier layer $(10 \mathrm{~nm})$ and $\mathrm{Mg}-$ doped $\mathrm{p}-\mathrm{GaN}$ layer $(60 \mathrm{~nm})$ with $\mathrm{Mg}$ concentration of $5 \times 10^{19}$ $\mathrm{cm}^{-3}$. The SiN layer (gate insulator) with thickness form 0 to $15 \mathrm{~nm}$ was deposited by PECVD on full wafers. Then Pd gates were directly e-beam evaporated on $\mathrm{SiN}$ layer. After that $\mathrm{SiN}$ was etched away by RIE using Pd metal as hard mask. p-GaN layer was selective etched in $\mathrm{BCl}_{3} / \mathrm{SF}_{6}$ to form the self-aligned MIS-gate structure. After the formation of device isolation area, the low temperature $\left(550{ }^{\circ} \mathrm{C}\right) \mathrm{Ta} / \mathrm{Al}$ based ohmic contacts are e-beam evaporated followed by $170 \mathrm{~nm}$ PECVD SiN. The device size is a gate length of $1 \mathrm{um}$, a gate width of $100 \mathrm{um}$ and a gate-drain distance of $6 \mathrm{um}$. The source-gate separation is $1 \mathrm{um}$.

The DC parameters of the fabricated GaN transistors were measured by HP4156A Semiconductor Parameter Analyser.

Fig. 1 shows a schematic view of the fabricated selfaligned MIS-gated GaN device structure. 


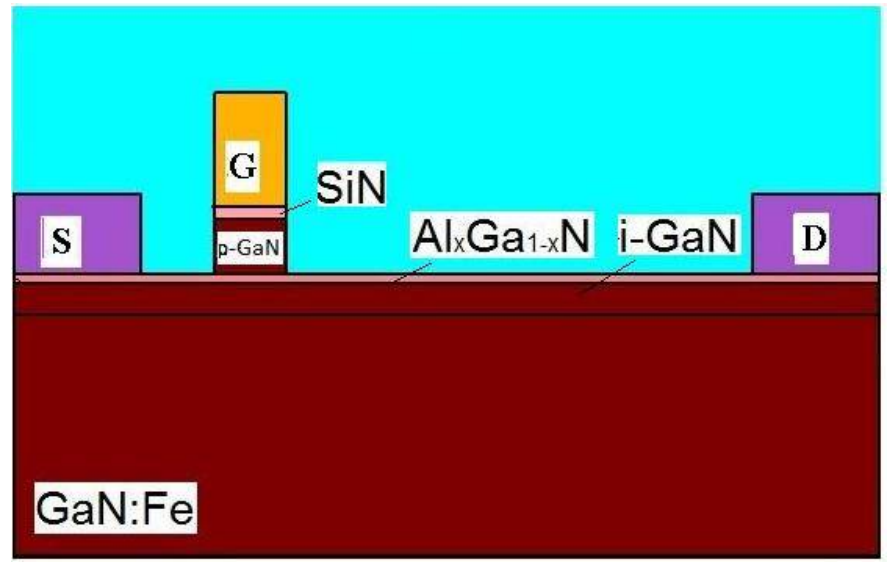

Fig. 1. Schematic view of MIS-gated GaN device structure.

\section{RESULTS}

Fig. 2 shows a band diagram of gate area. The double heterojunction is formed in $\mathrm{p}-\mathrm{GaN}$ gate region between $\mathrm{p}$ $\mathrm{GaN} / \mathrm{AlGaN}$ and $\mathrm{AlGaN} / \mathrm{GaN}$.

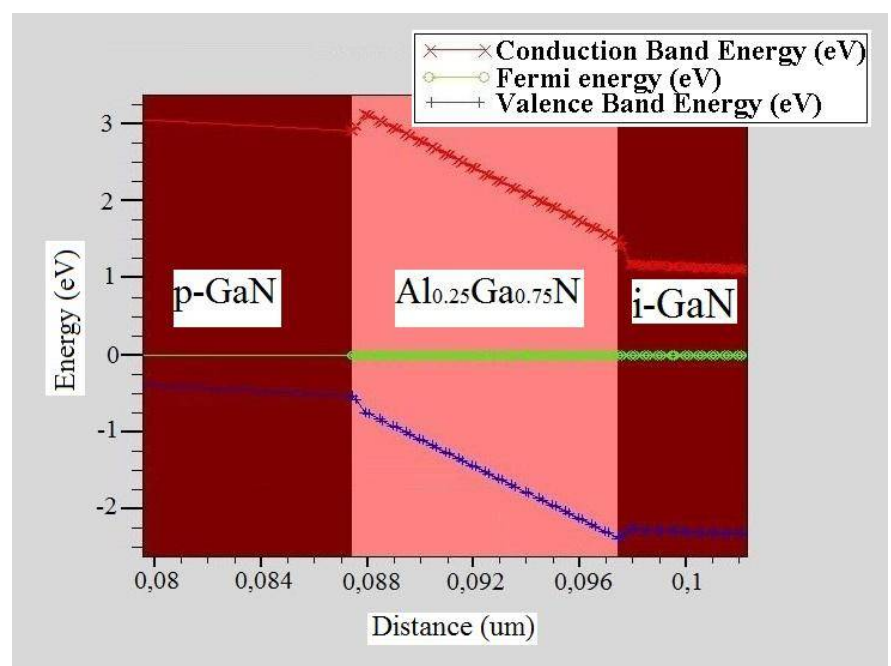

Fig. 2. Band diagram of model transistor

Fig. 3 shows the $I_{d s}-V_{g s}$ DC characteristics of fabricated AlGaN/GaN HEMTs. It can be seen that the Pd Schottky gated ( $\mathrm{SiN}$ : $0 \mathrm{~nm}$ ) GaN transistor has $\mathrm{V}_{\text {th }}=+1.5 \mathrm{~V}$ and subthreshold drain leakage current at $\mathrm{V}_{\mathrm{gs}}=0 \mathrm{~V}$ is $3 \mu \mathrm{A} / \mathrm{mm}$. The maximum drain current is $\mathrm{I}_{\mathrm{ds}}=0.52 \mathrm{~A} / \mathrm{mm}$ at $\mathrm{V}_{\mathrm{gs}}=15 \mathrm{~V}$.

The threshold voltage of MIS-gated HEMTs with SiN thickness of $5,10,15 \mathrm{~nm}$ is about $1.7 \mathrm{~V}, 3.8 \mathrm{~V}, 6.8 \mathrm{~V}$, respectively. It is visible from Fig. 3 that increase of $\mathrm{SiN}$ thickness in MIS-gate structure lead to reduce the magnitude of sub-threshold drain leakage current. It can be caused by the reduced trap density at the SiN/p-GaN interface after PECVD passivation. However MIS-gated GaN transistors with thick
$(15 \mathrm{~nm})$ insulator demonstrate the reduced maximum drain current $\mathrm{I}_{\mathrm{ds}}=0.25 \mathrm{~A} / \mathrm{mm}$ at $\mathrm{V}_{\mathrm{gs}}=15 \mathrm{~V}$.

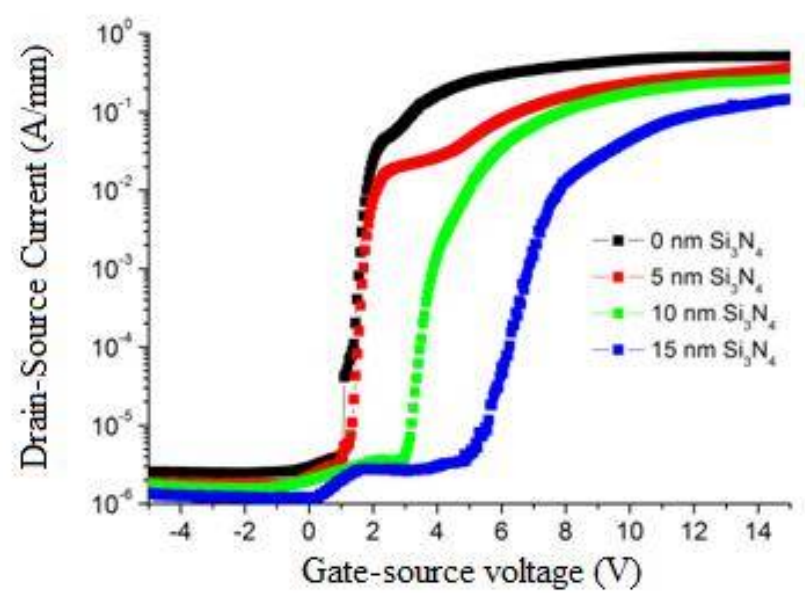

Fig. 3. Ids-Igs characteristics.

Fig. 4 shows $I_{g s}-V_{g s}$ characteristics. It can be seen that the fabricated p-gate GaN HEMT with Pd based Schottky contact has the high on-state gate current. The maximum gate swing is about $\mathrm{V}_{\text {gsmax }}=5-6 \mathrm{~V}$. Introduce the thin $\operatorname{SiN}$ layer $(5 \mathrm{~nm})$ between Schottky metal and p-GaN layer lead to significally reduce the on-state gate current and increase the gate swing to $\mathrm{V}_{\text {gsmax }}=12-15 \mathrm{~V}$. Further increase the SiN thickness lead to reduce on-state gate current. The fabricated self-aligned MISgates GaN HEMT with $15 \mathrm{~nm} \mathrm{SiN}$ insulator demonstrates the low on-state gate current $\mathrm{I}_{\mathrm{gs}}=0.1 \mu \mathrm{A} / \mathrm{mm}$ at $\mathrm{V}_{\mathrm{gs}}=15 \mathrm{~V}$.

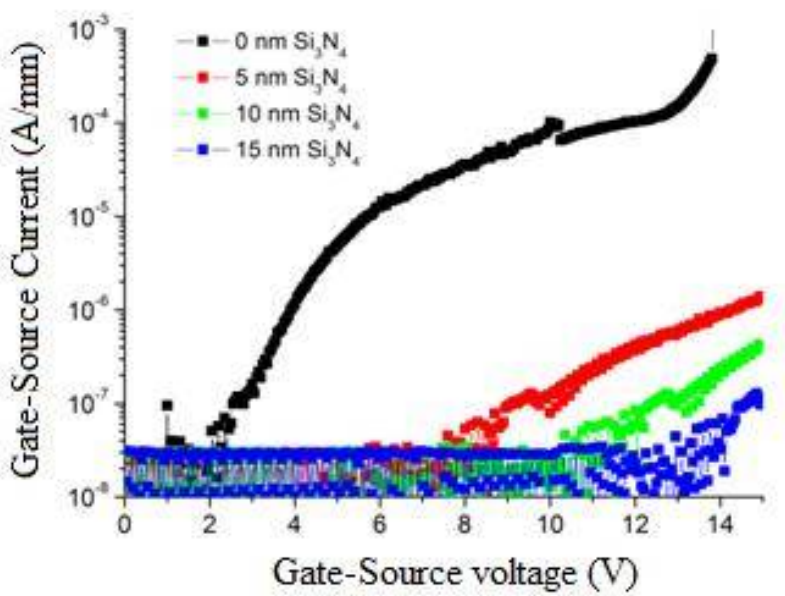

Fig. 4. Igs-Igs characteristics.

Fig. 5 shows the dependences of threshold voltage and maximum drain current from the $\operatorname{SiN}$ thickness $(0,5,10,15$ $\mathrm{nm}$ ) in MIS-gates GaN AlGaN/GaN HEMTs. Increase the SiN thickness from 0 to $15 \mathrm{~nm}$ lead to improve the threshold voltage value from $1.5 \mathrm{~V}$ to $6.8 \mathrm{~V}$. There is visible a linear decreasing of maximum drain current from the SiN thickness in MIS-gate structure. 
The p-doped GaN layer on top of the $\mathrm{AlGaN}$ barrier and the $\mathrm{GaN}$ channel form a pin-diode, this diode gradually started turning on upon increasing positive gate bias. The top Schottky type gate contact is in reverse polarity with respect to the semiconductor-junction pin-diode.

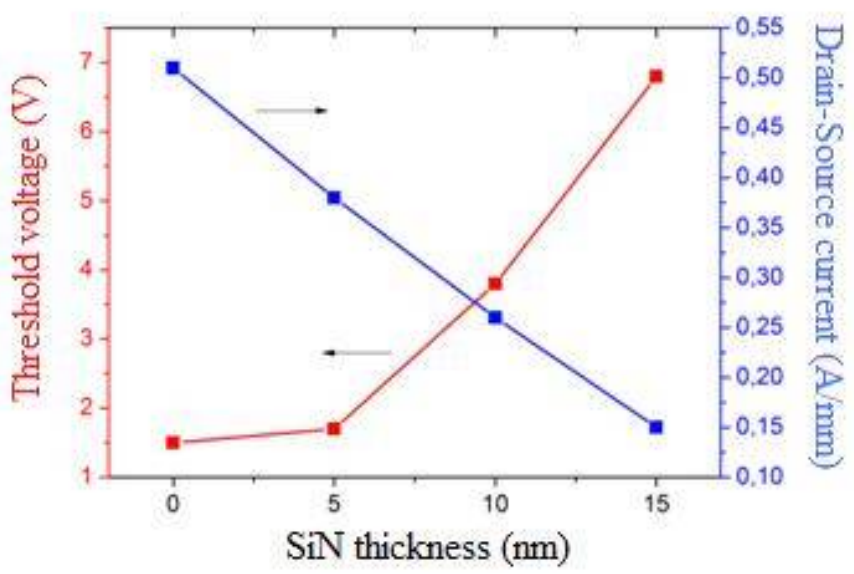

Fig. 5. Dependences of threshold voltage and maximum drain current from the SiN thickness in MIS-gated AlGaN/GaN HEMT.

Fig. 6 shows the equivalent circuits of (a) Schottky and (b) MIS-gated GaN HEMTs. The drain current is turned on when the gate voltage supplies to $\mathrm{AlGaN}$ capacitance $\left(\mathrm{C}_{\mathrm{AlGaN}}\right)$ becomes higher than the threshold voltage $\left(\mathrm{V}_{\mathrm{th}}\right)$, because the circuits are connected to gate $\mathrm{AlGaN}$ by two dimension electron gas (2DEG) when the threshold voltage is applied. The $V_{\text {th }}$ changes with the series capacitance when the gate insulator is inserted. The relationship between the $\mathrm{V}_{\text {th }}$ and total capacitance of MIS-gated HEMTs is shown in formula (1), in which $V_{\text {th }}$ (Schottky) is the $V_{\text {th }}$ of Schottky contact HEMTs, $\mathrm{V}_{\text {th }}$ (MIS) is the $\mathrm{V}_{\text {th }}$ of MIS-gated HEMT and $\mathrm{C}_{\text {ins }}$ is the insulator capacitance.

$$
\begin{aligned}
& C_{\text {AlGav }} \cdot V_{t h}(\text { Schottky })=C_{l n s} \cdot\left\{V_{t h}(\text { MIS })-V_{t h}(\text { Schottky })\right\} \\
& V_{t h}(M I S)=\frac{C_{A l G a N}+C_{\text {lns }} \cdot V_{t h}(\text { Schottky })}{C_{l n s}}
\end{aligned}
$$
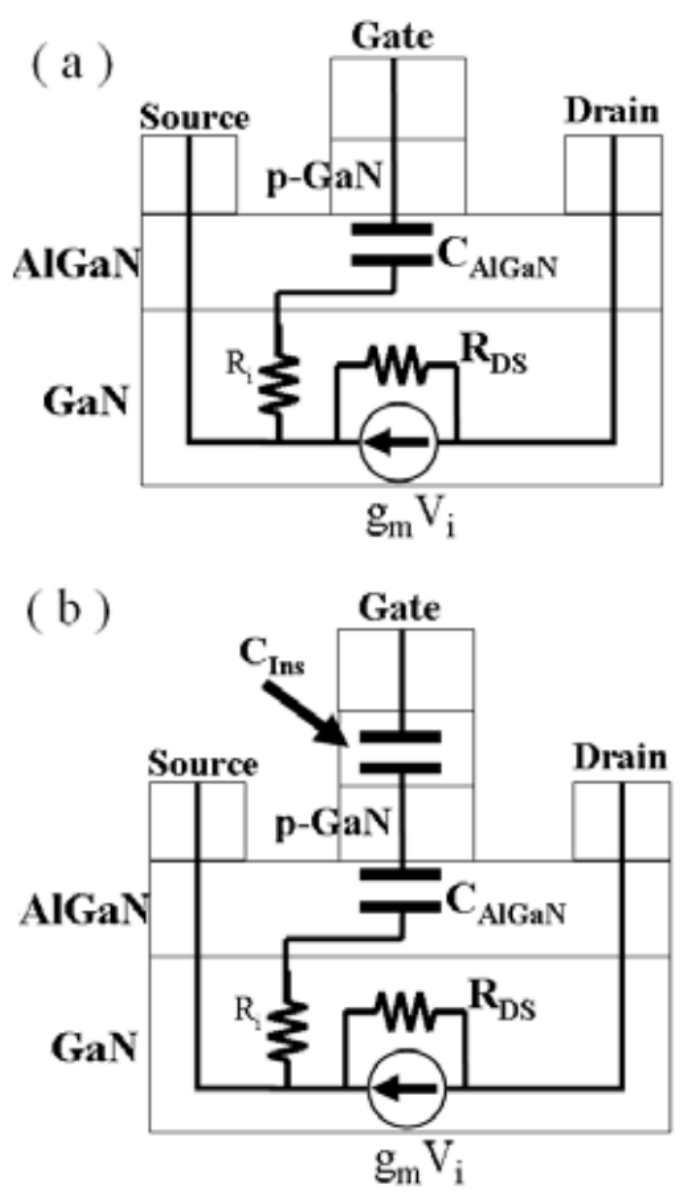

Fig. 6. Equivalent circuits of Schottky and MIS-gates GaN HEMTs.

Fig. 7 shows the experimental results of $\mathrm{SiN}$ thickness and $\mathrm{V}_{\text {th }}$. The broken line shows the results of TCAD simulation. The experimental results almost coincide with the results of simulation.

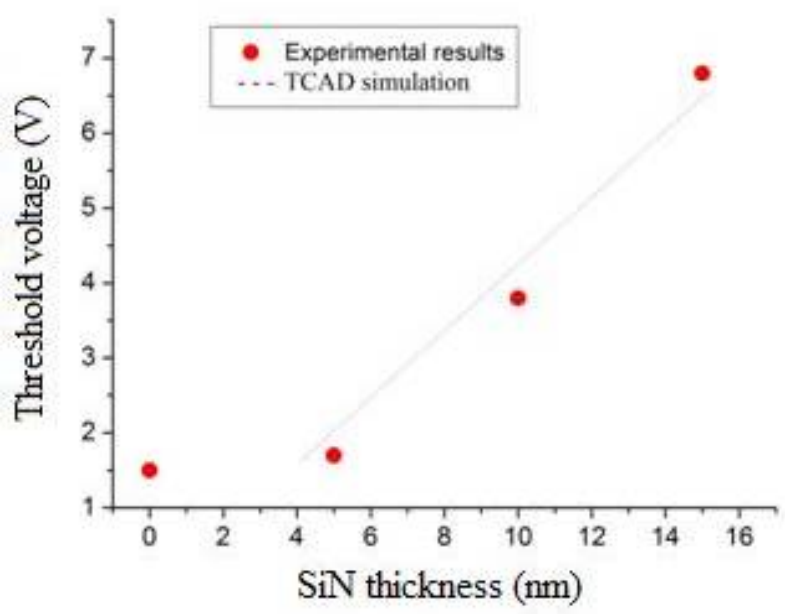

Fig. 7. Dependences of threshold voltage from SiN thickness of MIS-gated AlGaN/GaN HEMT from TCAD simulation and experimental results. 
There known two different concepts to produce normallyoff GaN devices: Schottky and Ohmic p-gate devices. Panasonic [15] - [16] and FBH [17] - [19] are used the Ohmic contact to p-GaN layer, but Samsung [20] and IMEC [21] are used the $\mathrm{W}$ and TiN based Schottky gate contacts. A detailed investigation of the impact of gate metal on the performance of $\mathrm{p}-\mathrm{GaN} / \mathrm{AlGaN} / \mathrm{GaN}$ transistors was presented in [22]. The authors of this study demonstrated that the work function of the gate metal has a critical impact on the electrical parameters of the devices, such as off-state leakage, forward operation current and threshold voltage. Several gate metals $(\mathrm{Ni} / \mathrm{Au}$, $\mathrm{Ti} / \mathrm{Au}$ and $\mathrm{Mo} / \mathrm{Ti} / \mathrm{Au}$ ) were compared, to discuss the importance of the trade-off between $V_{\text {th }}$ and output drain current. According the data from Fig. 7, in this work Schottky based MIS-gated GaN transistors with different insulator layer thickness $(5,10,15 \mathrm{~nm})$ demonstrate the better $V_{\text {th }}-I_{d s s}$ performance.

Moreover, using MIS-gate in $\mathrm{p}-\mathrm{GaN}$ transistors is possible to obtain very low on-state gate current values up to a gate voltage of $15 \mathrm{~V}$ (fig. 4), which is preferred for reliability and for compability with gate drivers, that are often designed for insulated gate technologies and to lower the power consumption (i.e. high gate leakage is associated with a continuous power consumption and associated heating of the gate driver).

\section{CONCLUSIONS}

High voltage enhanced mode GaN transistors is a basic element for power electronic applications. For achieving normally-off operation p-type GaN gate structures are used. The optimized epitaxial designs enable threshold voltage close to $+2 \mathrm{~V}$. In present work, it was shown that SiN gate insulator introduced into $\mathrm{p}-\mathrm{GaN}$ gate HEMT lead to increase the threshold voltage up to $+6.8 \mathrm{~V}$. The threshold voltage can be controlled by changing the thickness of SiN layer. The subthreshold and on-state gate currents were decreased. Therefore, DC power loss of the input signal was decreased.

\section{ACKNOWLEDGMENT}

The authors would like to thank the staff of the Microelectronics Department of Micran Research and Production Company and the Research and Education Nanotechnology Center of Tomsk state University of Control systems and radio electronics for their useful discussions and assistance with the work.

This work was financially supported by the Ministry of Education and Science of the Russian Federation, agreement no. 14.577.21.0250 from 26.09.17, unique project identifier is RFMEFI57717X0250.

\section{REFERENCES}

[1] Marcon, D., De Jaeger, B., Halder, S., Vranckx, N., Mannaert, G., Van Hove, M., Decoutere, S., "Manufacturing Challenges of GaN-on-Si HEMTs in a $200 \mathrm{~mm}$ CMOS Fab",
Semiconductor Manufacturing, IEEE Transactions on, vol. 26, No. 3, 2013.

[2] Hilt, O., Knauer, A., Brunner, F., Würfl, J. "Normally-off AlGaN/GaN HFET with p-type GaN Gate and AlGaN Buffer", In Proceedings of the 22nd International Symposium on Power Semiconductor Devices and ICs, Hiroshima, Japan, 16-18 March 2010.

[3] Chen, K.J.; Zhou, C., "Enhancement-mode AlGaN/GaN HEMT and MIS-HEMT technology", Phys. Status Solidi Appl. Mater, vol. 208, pp. 434-438, 2011.

[4] Bisi, E.D.; Meneghini, M.; Marino, F.A.; Marcon, D.; van Hove, S.S.M.; Decoutere, S.; Meneghesso, G. "Kinetics of Buffer-Related $\mathrm{R}_{\mathrm{ON}}$-Increase in GaN-on-Silicon MIS-HEMTs“, IEEE Electron Device Lett. vol. 35, pp. 1004-1006, 2014.

[5] Woojin Choi, Ogyun Seok, Hojin Ryu, Ho-Young Cha, Kwang-Seok Seo, "High-Voltage and Low-Leakage-Current Gate Recessed Normally-Off GaN MIS-HEMTs With Dual Gate Insulator Employing PEALD- SiN /RF-Sputtered- $\mathrm{HfO}_{2} "$, IEEE Electron Device Letters, vol. 35, no. 2, 2014.

[6] Bisi, D., Meneghini, M., Van Hove, M., Marcon, D., Stoffels, S., Wu, T.; Decoutere, S., Meneghesso, G., Zanoni, E, "Trapping mechanisms in GaN-based MIS-HEMTs grown on silicon substrate", Phys. Status Solidi, vol. 212, 2015.

[7] Bisi, D.; Meneghini, M.; Van Hove, M.; Marcon, D.; Stoffels, S.; Wu, T.; Decoutere, S.; Meneghesso, G.; Zanoni, E. "Trapping mechanisms in GaN-based MIS-HEMTs grown on silicon substrate, " Phys. Status Solidi. vol. 212, pp. 11221129, 2015.

[8] Lagger P, Ostermaier C., Pobegen D, and Pogany D, "Towards understating the origin of threshold voltage instability of AlGaN/GaN MIS-HEMTs," in Proc. IEEE IEDM, 2012.

[9] Lagger, P., Reiner, M., Pogany, D., Ostermaier, C, "Compare bias-induced threshold voltage drifts in GaN based MISHEMT”, IEEE Electron Devices, vol. 61, no. 4, 2014.

[10] Meneghini, M., Rossetto, I., Bisi, D., Ruzzarin, M., Van Ho, Meneghesso, G., et al., "Negative Bias-Induced Threshold", IEEE Electron Device Lett. vol.37, no.12, 2016.

[11] Wu, T., Marcon, D., De Jaeger, B., Van Hove, M., Bakeroot, B., Stoffels, S., Groeseneken, G., Decoutere, S., Roelofs, R., "Time dependent dielectric breakdown (TDDB) evaluation of PE-ALD SiN gate dielectrics on AlGaN/GaN recessed gate Dmode MIS-HEMTs and E-mode MIS-FETs", In Proceedings of the IEEE International Reliability Physics Symposium, Monterey, CA, USA, 2015.

[12] Lagger, P.; Reiner, M.; Pogany, D.; Ostermaier, C. "Comprehensive study of the complex dynamics of forward bias-induced threshold voltage drifts in GaN based MISHEMTs by stress/recovery experiments", IEEE Trans. Electron Devices, vol. 61, pp. 1022-1030, 2014.

[13] Meneghini, M.; Rossetto, I.; Hurkx, G.A.; Sonsky, J.; Croon, J.A.; Meneghesso, G.; Zanoni, E. "Extensive Investigation of Time-Dependent Breakdown of GaN-HEMTs Submitted to Off-State Stress“, IEEE Trans. Electron Devices, vol.62, pp. 2549-2554, 2015.

[14] Ruzzarin, M.; Meneghini, M.; Member, S.; Rossetto, I.; Van Hove, M.; Stoffels, S.; Wu, T.; Decoutere, S.; Meneghesso, G. "Evidence of Hot-Electron Degradation in GaN-based MISHEMTs Submitted to High Temperature Constant Source Current Stress“, IEEE Electron Device Lett. 2016, in press.

[15] Uemoto, Y., Hikita, M., Ueno, H., Matsuo, H., Ishida, H., Yanagihara, M., Ueda, T., Ueda, D., Tanaka, T. "Gate Injection Transistor (GIT) - A Normally-Off AlGaN/GaN Power Transistor Using Conductivity Modulation", IEEE Trans. Electron Devices, vol. 54, no. 7, 2007. 
[16] Okita, H.; Hikita, M.; Nishio, A.; Sato, T.; Matsunaga, K. "Through Recessed and Regrowth Gate Technology for Realizing Process Stability of GaN-GITs“, In Proceedings of the 28th International Symposium on Power Semiconductor Devices and ICs, Prague, Czech Republic, 12-16 June 2016; pp. 23-26.

[17] Hilt, O.; Zhytnytska, R.; Böcker, J.; Bahat-Treidel, E.; Brunner, F.; Knauer, A. "70 mOhm/600 V Normally-off GaN Transistors on $\mathrm{SiC}$ and $\mathrm{Si}$ Substrates", In Proceedings of the 27th International Symposium on Power Semiconductor Devices and ICs, Kowloon Shangri-La, Hong Kong, China, 10-14 May 2015; pp. 237-240.

[18] Hilt, O.; Bahat-Treidel, E.; Cho, E.; Singwald, S.; Würfl, J. "Impact of buffer composition on the dynamic on-state resistance of high-voltage $\mathrm{AlGaN} / \mathrm{GaN}$ HFETs", In Proceedings of the IEEE International $24^{\text {th }}$ International Symposium on Power Semiconductor Devices and ICs, Bruges, Belgium, 3-7 June 2012; pp. 345-348.

[19] Würfl, J.; Hilt, O.; Zhytnytska, R.; Kotara, P.; Brunner, F.; Krueger, O.; Weyers, M. "Techniques towards GaN power transistors with improved high voltage dynamic switching properties", In Proceedings of the IEEE International Electron Devices Meeting, Washington, DC, USA, 9-11 December 2013.

[20] Kim, J.; Hwang, S.; Hwang, I.; Choi, H.; Chong, S.; Choi, H.; Jeon,W.; Soon, H.; Kim, J.Y.; Park, Y.H.; et al. "High Threshold Voltage p-GaN Gate Power Devices on $200 \mathrm{~mm} \mathrm{Si}$. ", In Proceedings of the 25th International Symposium on Power Semiconductor Devices and ICs, Kanazawa, Japan, 2630 May 2013.

[21] Wu, T.; Member, S.; Marcon, D.; You, S.; Posthuma, N.; Bakeroot, B.; Stoffels, S.; Van Hove, M.; Groeseneken, G.; Decoutere, S. "Forward Bias Gate Breakdown Mechanism in Enhancement-Mode p-GaN Gate $\mathrm{AlGaN} / \mathrm{GaN}$ High-Electron Mobility Transistors“, IEEE Electron Device Lett., vol. 36, pp. 1001-1003, 2015.

[22] High, G.; Lee, F.; Su, L.;Wang, C.;Wu, Y.; Huang, J.; Member, S. "Impact of Gate Metal on the Performance Mobility Transistors“, IEEE Electron Device Lett., vol. 36, pp. 232-234, 2015. 